\title{
An Evaluation of Qualities of Nuclear Medicine Technology Programs and Graduates Leading to Employability
}

\author{
Cybil J. Nielsen, Sarah S. Brosmer, Patrick J. Byrne, and S. Gregory Jennings \\ Indiana University School of Medicine, Indianapolis, Indiana
}

\begin{abstract}
Our rationale was to evaluate how the qualities of nuclear medicine technology (NMT) programs and graduates associate with employability. Methods: We identified all Nuclear Medicine Technology Certification Board applicants who passed the entry-level NMT examination between 2012 and 2017. Certificants were e-mailed a survey with questions on graduate qualities, program qualities, and initial employment. Each quality was quantified. Age, sex, and desired employment within or outside the United States were also documented. An employability scale was created from the initial employment questions. Subjects were separated into 4 employability groups based on their employability score: poorly employable, marginally employable, satisfactorily employable, and optimally employable. An ANOVA test was performed on each quality using the 4 employability groups; a $P$ value of less than 0.05 was considered significant. Results: Of the 3,930 surveys distributed, 885 (22.5\%) were completed and returned. Six of the 10 qualities evaluated were significantly associated with employability: overall education $(P<0.01)$, number of clinic hours $(P<0.01)$, grade-point average $(P<0.01)$, number of schools within a 100 -mile $(161-\mathrm{km})$ radius $(P<0.01)$, number of attempts to pass the board examination $(P<0.01)$, and number of clinics $(P=0.04)$. The qualities that were not statistically significant were age, sex, employment location sought, board score, single versus dual certification, program level of education, and number of graduates in the class. Conclusion: There are multiple graduate and program qualities that are predictive of the employability of NMT graduates.
\end{abstract}

Key Words: employability; nuclear medicine technology programs; initial employment

J Nucl Med Technol 2019; 47:29-34

DOI: $10.2967 /$ jnmt.118.219519

B oth the students and the faculty of nuclear medicine technology (NMT) programs want to know what they can do to ensure success on graduation. One measure of success is the employability of the program's graduates. For student recruit-

Received Aug. 21, 2018; revision accepted Sep. 11, 2018.

For correspondence or reprints contact: Cybil Nielsen, Nuclear Medicine Technology Program, Department of Radiologic and Imaging Sciences, Indiana University School of Medicine, 1120 W. Michigan St., CL-120, Indianapolis, IN 46202.

E-mail: cybniels@iupui.edu

Published online Nov. 9, 2018

COPYRIGHT (C) 2019 by the Society of Nuclear Medicine and Molecular Imaging. ment and continuing accreditation purposes, program directors must assist students in employment placement (1).

There are numerous student and program qualities that may be predictive of employability. One such quality that has received much attention is level of education. In 2005, the Society of Nuclear Medicine and Molecular Imaging Technologist Section recommended that entry-level education into the field be at the baccalaureate-degree level, effective in 2015 (2). But as of 2012 , only $46 \%-60 \%$ of NMTs held baccalaureate or more advanced degrees $(3,4)$. To our knowledge, the benefit of obtaining a higher degree has not been evaluated in terms of employability.

Grade point average (GPA) is used by many programs as an admission criterion. Although a study in 2009 compared admission criteria (including GPA) and student success for medical radiation sciences programs (5), they did not evaluate the use of GPA for the employability of students after graduation, either before or during NMT training.

Other qualities may be program-specific; because NMT programs do not have standardized programs of study, there is much variation in the level of education required at admission, in class size, in number of clinical hours, and in number of clinical sites (6). In a 2016 study comparing the number of clinical sites and job placement rates, no relationship between them was seen (1), but the other qualities have not been studied. Another issue is single versus dual certification. In 2008, the Society of Nuclear Medicine and Molecular Imaging Technologist Section added CT to the recommended curriculum for educational programs (7). As programs add CT to the curriculum, the employability of dual-certified graduates needs to be evaluated.

Another metric that may be compared with employability is passing the entry-level examination on the first attempt. Until 2017, the Nuclear Medicine Technology Certification Board (NMTCB) used 3 passing levels (pass, pass with distinction, and pass with highest distinction) for its entry-level examination. To our knowledge, no one has looked at employability based on passing the entry-level examination on the first attempt, or distinction level.

Age and sex are 2 qualities that cannot be controlled. In 2013, the NMTCB conducted a salary survey, which showed slightly higher salaries for men and for older individuals (8). However, the authors did not compare employability by sex. In terms of age, the survey did reveal that salary increased 


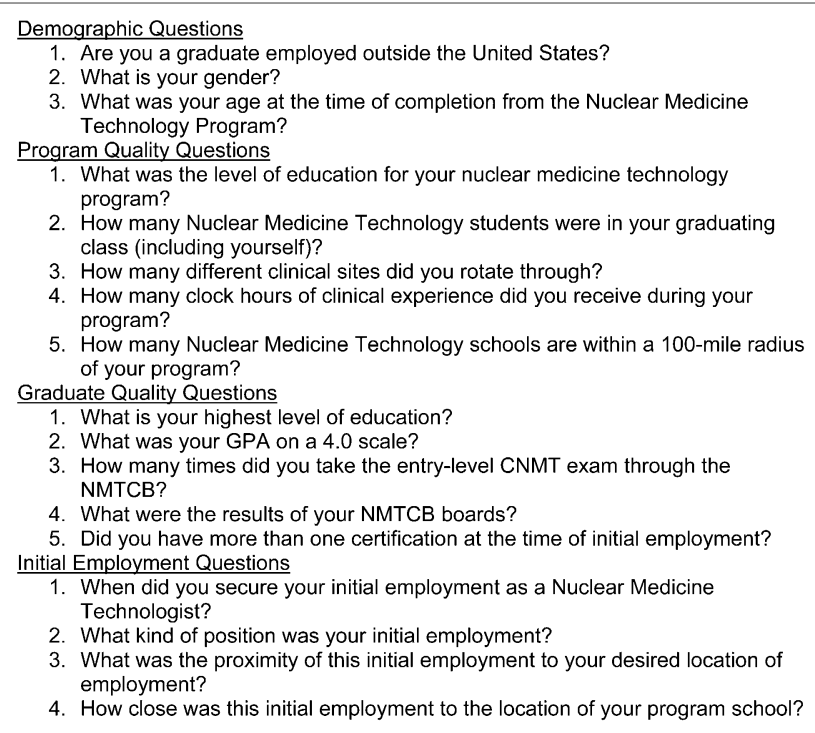

FIGURE 1. Questions related to demographics, program and graduate qualities, and initial employment.

as years of experience increased. It also showed that salary increased as the age of the respondent increased (8). However, it did not look at age independent of years of experience.

The job market for new NMTs has been depressed for several years. Understanding the impact of different qualities on employability will allow program directors to focus on key areas to help students successfully find employment. Students and program leaders may be able to effect the qualities needed to graduate with higher employability success. But qualities that lead to optimal employability have not been systematically evaluated. The purpose of this study was to determine the association between employability and qualities of NMT graduates and programs.

\section{MATERIALS AND METHODS}

Institutional Review Board approval was sought, and this study was determined to have exempt status. The study complied with the Health Insurance Portability and Accountability Act guidelines.

FIGURE 2. Employability scale used to calculate employability scores for individual subjects. $\mathrm{PRN}=$ as needed.
TABLE 1

Employability Score, Category, and Number of Subjects

\begin{tabular}{llr}
\hline Score & \multicolumn{1}{c}{ Category } & \multicolumn{1}{c}{ Subjects $(n)$} \\
\hline 0 & Poorly employable & $99(11.2 \%)$ \\
$1-59$ & Marginally employable & $264(29.8 \%)$ \\
$60-75$ & Satisfactorily employable & $297(33.6 \%)$ \\
$76+$ & Optimally employable & $225(25.4 \%)$ \\
\hline
\end{tabular}

An email list was obtained from the NMTCB including everyone $(n=3,930)$ who passed the entry-level NMT examination between January 2012 and December 2016. We developed a survey using REDCap online software. The survey included questions about demographics, NMT program qualities, NMT graduate qualities, and initial employment obtained in the NMT field (Fig. 1). Demographic data included sex, age, and whether initial employment was sought within or outside the United States. Qualities for NMT programs included program level of education, number of graduates in the class, number of clinical sites rotated through, number of clinical clock hours done while in the NMT program, and number of NMT programs within a 100 -mile $(161-\mathrm{km})$ radius of their program. Qualities for NMT graduates included highest level of education, GPA, number of attempts to pass the board examination, board score (pass, pass with distinction, or pass with highest distinction), and single versus dual certification. Employment questions included time from graduation to initial employment, type of NMT position (full-time, part-time, per diem), proximity of employment to desired location, and proximity of employment to school program. For each question, a quantitative score was given.

For education (both overall and program level), a score of 1 was given for a certificate, 2 was given for an associate's degree, 3 was given for a baccalaureate degree, 4 was given for a master's degree, and 5 was given for a doctoral degree. For number of clinical hours, a score of 1 was given for $0-250 \mathrm{~h}$, a score of 2 was given for 251$500 \mathrm{~h}$, a score of 3 was given for 501-750 h, a score of 4 was given for 751-1,000 h, a score of 5 was given for 1,001-1,250 h, a score of 6 was given for 1,251-1,500 h, and a score of 7 was given for greater than 1,500 h. For GPA, a score of 1 was given for 1.99 or below, a score of 2 was given for 2.00-2.49, a score of 3 was given for 2.50-2.99, a score of 4 was given for 3.00-3.49, a score of 5 was given for 3.50-3.99, and a score of 6 was given for 4.0 or greater. For results on NMTCB boards, a score of 1 was given for a pass, a score of 2 was given for a pass with distinction, and a score of 3 was given for a pass with highest distinction.

A 100-point employability scale was created using initial employment questions (Fig. 2).

Subjects who did not complete the survey were sent an email reminder every $5 \mathrm{~d}$ for a total of $20 \mathrm{~d}$. Data were collected and analyzed using REDCap software.

Subjects were divided into 4 employablility groups based on their employability score: poorly employable (0), marginally employable

TABLE 2

Subject Demographics Compared with Employability

\begin{tabular}{lcc}
\hline Demographic & $P$ & $r$ \\
\hline Age & 0.123956 & -0.07856 \\
Sex & 0.195393 & 0.048852 \\
International & 0.330178 & -0.05477 \\
\hline
\end{tabular}


TABLE 3

Graduate Qualities Compared with Employability

\begin{tabular}{lcc}
\hline \multicolumn{1}{c}{ Quality } & $P$ & $r$ \\
\hline Overall education & 0.003107 & 0.034391 \\
GPA & 0.002007 & 0.118697 \\
Number of board attempts & 0.000427 & -0.14134 \\
Board score (distinction level) & 0.204388 & 0.077608 \\
Dual certification & 0.354562 & -0.00073 \\
\hline
\end{tabular}

TABLE 4

Program Qualities Compared with Employability

\begin{tabular}{lll}
\hline \multicolumn{1}{c}{ Quality } & \multicolumn{1}{c}{$P$} & \multicolumn{1}{c}{$r$} \\
\hline Program education & 0.65737617 & 0.03465843 \\
Number of graduates & 0.692571 & -0.0172 \\
Number of clinics & 0.039616 & 0.07667 \\
Number of clinical hours & 0.002089 & 0.070851 \\
Number of schools within & 0.003685 & -0.09676 \\
100-mile radius & & \\
\hline
\end{tabular}

(1-59), satisfactorily employable (60-75), and optimally employable $(>75)$.

Demographics, program qualities, and graduate qualities were compared among the 4 employability groups using an ANOVA test. A $P$ value of less than 0.05 represented statistical significance and revealed a difference in employability based on that quality or demographic. A correlation analysis was also performed on all qualities and demographics when compared with employability. Descriptive statistics were performed on all 4 employability groups, as well as demographic data. For all program and graduate qualities that revealed statistical significance, a new scale-corrected score was assigned (between 0 and 345). The qualities with positive correlations were added, and the qualities with negative correlations were subtracted. They were then divided into the 4 employability categories, and an ANOVA test was done. A $P$ value of less than 0.05 represented statistical significance.

\section{RESULTS}

Of the 3,930 surveys sent out from the NMTCB email list, 885 were completed, for a return rate of $22.5 \%$. The

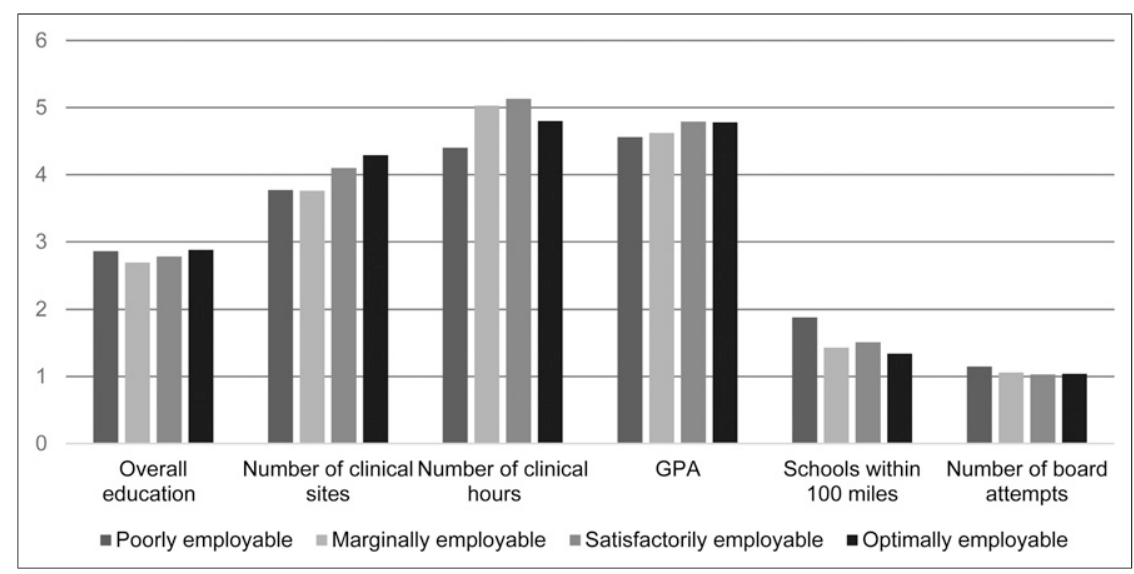

FIGURE 3. Qualities that affect employability. number of women returning the survey was 593 (67\%), and the number of men was $292(33 \%)$. The age distribution was as follows: $474(53.6 \%)$ were aged 18-25 y, $254(28.7 \%)$ were aged 26-33 y, 97 (10.97\%) were aged 34-41 y, and 60 $(6.79 \%)$ were aged $41 \mathrm{y}$ or older. The number of respondents securing employment as an NMT was 785 (88.8\%). The number in each employability group is given in Table 1.

There were 84 subjects who sought NMT employment outside the United States. Of these, 79 (94.05\%) gained such employment. There were 801 subjects who sought employment within the United States, 707 (88.26\%) of whom gained such employment.

There was no significant correlation between employability group and age, sex, or whether U.S. employment was sought. The following 6 qualities were significantly associated with employability: overall education $(P<0.01)$, number of clinical sites rotated through $(P=0.04)$, number of clinical hours performed $(P<0.01)$, GPA $(P<0.01)$, number of schools within a 100 -mile radius $(P<0.01)$, and number of attempts to pass the board examination $(P<0.01) . P$ values and correlation coefficients are listed in Tables 2-4. Employability showed an inverse relationship with number of attempts to pass the board examination and number of schools within a 100-mile radius.

The qualities that were not statistically significant were board score (level of distinction), single versus dual certification, program level of education, and number of graduates in the class.

Descriptive statistics were analyzed for the 6 qualities that had $P$ values of less than 0.05 . Table 4 shows the mean for each quality, broken down by employability category.

For overall education, the mean was highest for the poorly employable and optimally employable categories. For number of clinical sites, the mean increased as employability increased. For number of clinical hours, the top 3 employability categories yielded mean scores close to 5 (1,001-1,250 clock hours). The poorly employable category yielded a mean score closer to 4 (751-1,000 clock hours). For GPA, the mean score increased as employability increased. For number of schools within a 100-mile radius, the highest mean appeared in the poorly employable category and the lowest mean appeared in the optimally employable category. For number of attempts to pass the board examination, the highest mean appeared in the poorly employable category (Fig. 3).

The 6 qualities that yielded a $P$ value of less than 0.05 (Table 5) were evaluated together. The qualities were scale-corrected to between 0 and 345 . Those with a positive correlation were 
TABLE 5

Mean for Qualities That Yielded $P$ Value of Less Than 0.05

\begin{tabular}{|c|c|c|c|c|}
\hline Quality & Poorly employable & Marginally employable & Satisfactorily employable & Optimally employable \\
\hline Overall education* & $2.8586(0.6852)$ & $2.6906(0.5728)$ & $2.7778(0.5734)$ & $2.875(0.5542)$ \\
\hline Number of clinics ${ }^{\dagger}$ & $3.7677(2.0841)$ & $3.7547(2.1205)$ & $4.1010(2.0251)$ & $4.2857(2.3214)$ \\
\hline Number of clinical hours* & $4.4040(1.8677)$ & $5.0334(1.7153)$ & $5.1313(1.7202)$ & $4.8036(1.8085)$ \\
\hline $\mathrm{GPA}^{*}$ & $4.5556(0.7454)$ & $4.6226(0.7494)$ & $4.7914(0.6903)$ & $4.7813(0.6639)$ \\
\hline $\begin{array}{l}\text { Number of schools within } \\
100 \text {-mile radius }\end{array}$ & $1.8788(1.2958)$ & $1.4302(1.2747)$ & $1.5017(1.2140)$ & $1.3393(1.2169)$ \\
\hline Number of board attempts* & $1.1515(0.4371)$ & $1.0641(0.2746)$ & $1.0269(0.1622)$ & $1.0446(0.2276)$ \\
\hline $\begin{array}{l}{ }^{*} P<0.01 . \\
{ }^{\dagger} P=0.04 . \\
\text { Data in parentheses are SD. }\end{array}$ & & & & \\
\hline
\end{tabular}

summed, those with a negative correlation were subtracted, and a new overall score was created for these 6 categories (Table 6).

This new score was separated using the same employability score, and an ANOVA test was run. The $P$ value for those 6 qualities was 0.000000479 . Figure 4 shows a box plot for the 6 qualities with a $P$ value of less than 0.05 .

There was a weak but not statistically significant decrease in employability with age (correlation, -0.07) (Fig. 5).

Although there was no significant difference in employability with regard to sex, there was a small positive correlation for sex (0.05). Men had a higher percentage in the poorly employable category, whereas women had a higher percentage in the satisfactorily and optimally employable categories (Fig. 6).

Although there was no significant difference in employability with regard to employment sought within the United States versus elsewhere, there was a small negative correlation $(-0.05)$. The percentage of those who sought employment outside the United States was higher for the satisfactorily employable and optimally employable categories and lower for the poorly employable and marginally employable categories (Fig. 7).

\section{DISCUSSION}

Our study has shown that there are multiple, often controllable factors that affect the employability of NMT

TABLE 6

Scale-Corrected Scores for 6 Factors Significantly Associated with Employability

\begin{tabular}{cccc}
\hline \multicolumn{1}{c}{ Factor } & Median & Mean & SD \\
\hline $\begin{array}{c}\text { Poorly employable } \\
(n=99)\end{array}$ & 173 & 172.3838 & 58.5759 \\
$\begin{array}{c}\text { Marginally employable } \\
(n=264)\end{array}$ & 193 & 193.0717 & 55.2589 \\
$\begin{array}{c}\text { Satisfactorily employable } \\
(n=297)\end{array}$ & 207 & 202.5118 & 51.8757 \\
$\begin{array}{c}\text { Optimally employable } \\
(n=224)\end{array}$ & 215 & 205.5291 & 57.1893 \\
\hline
\end{tabular}

program graduates. These include the overall education of the admitted students, the number of clinical sites rotated through, the number of clinical hours performed, the GPA of admitted students, the number of schools within a 100mile radius, and the number of board attempts. Other factors sometimes thought to be predictors of employment success were found not to be so. These include age, sex, program level of education (certificate, associate, or baccalaureate degree), single versus dual certification, and class size.

NMT program directors may be able to increase the employability of their graduates if they adapt their programs to offering at least 1,000 clinical hours. For administrators considering the development of new NMT programs, they should consider the availability of other programs within a 100-mile radius, because the existence of multiple programs in close proximity tends to decrease the employability of their graduates. Programs that offer students multiple experiences at different clinical sites also lead to an increase in employability.

NMT students may be able to increase their employability with increased education. Although the level of education of their program is not statistically significant, their overall education is. The higher the education, the more employable they are. Students should also focus on

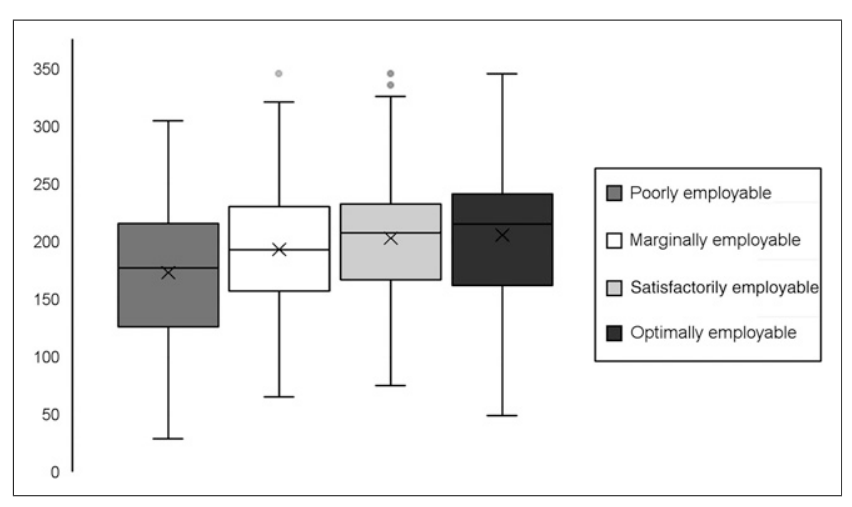

FIGURE 4. Box plot for scale-corrected scores for 6 factors significantly associated with employability. 


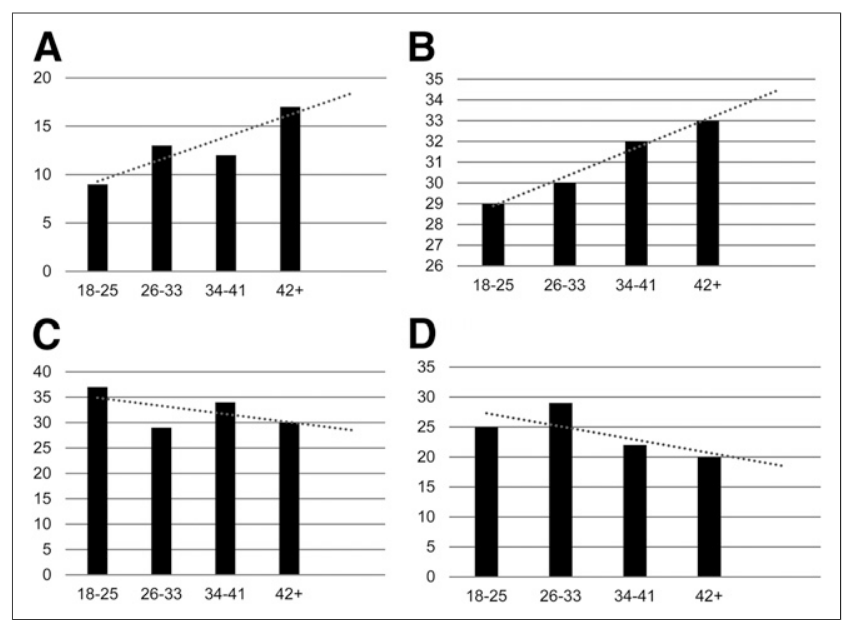

FIGURE 5. Percentage employable by employability category and age, where age is on $x$-axis and employability is on $y$-axis: poorly employable $(A)$, marginally employable $(B)$, satisfactorily employable (C), optimally employable (D).

their GPA. The higher their GPA, the more employable they are. They should also strive to pass the entry-level examination on their first attempt. Knowledge by potential employers that the student required more than one attempt to pass the examination appears to affect their willingness to hire that student. Students should not focus on the score they receive on the board examination because there was no statistical significance among those who passed, those who passed with distinction, and those who passed with highest distinction.

Education level in the NMT program was not found to be predictive of employability. Yet there have been multiple recent surveys on this topic, with widely varying results. In 2012, the NMTCB surveyed 21,383 active certificants. The overall educational breakdown in that survey was that $9.2 \%$ held a certificate or diploma, $20.08 \%$ held an associate's degree, $48.67 \%$ held a baccalaureate degree, $9.41 \%$ held a master's degree, and just less than $1 \%$ held a doctoral or postdoctoral degree (3). The American Society of Radiologic Technologists conducted an enrollment survey in 2016, and the society's enrollment snapshot also found that most programs' level of education is an associate's degree (4). Although there has been a push by some stakeholders to increase the entry-level education of NMTs to the

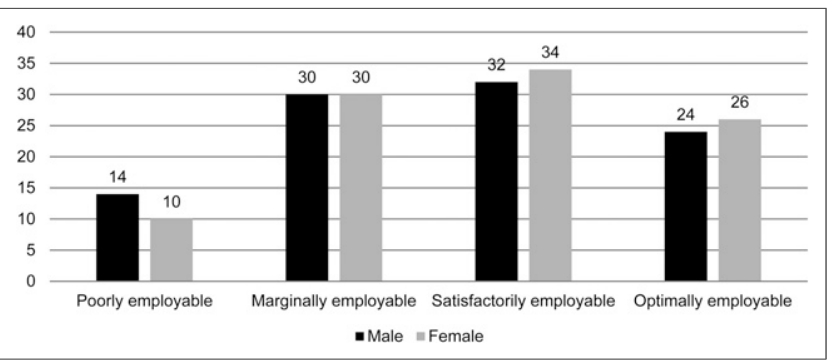

FIGURE 6. Percentage of each employability category by sex.

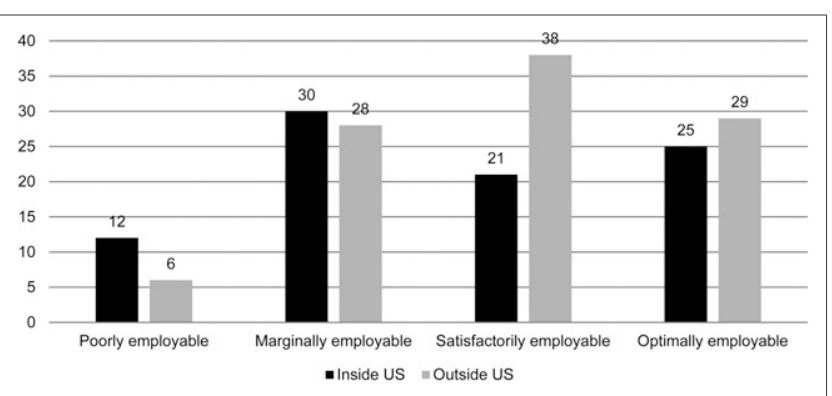

FIGURE 7. Percentage used inside and outside United States by employability category.

baccalaureate degree, this study found that it is the overall education of the NMT, not the program-level education, that leads to a higher degree of employability.

Single versus dual certification did not affect employability in this study. This finding was seen despite a push within the NMT educational community to emphasize training in CT. On August 4, 2007, a CT consensus conference occurred with stakeholders to discuss who would be doing CT. A consensus statement was established that stated, "CT has become a core skill for nuclear medicine technologists when using hybrid technology" (9). In 2007, the Society of Nuclear Medicine and Molecular Imaging Technologist Section added performance of CT scans and the administration of contrast for these scans to the scope of practice for NMTs. However, this study did not reveal that dual certification led to a greater degree of employability, at least for initial employment.

We found that neither age itself nor sex affected employability. A recent survey of age and sex differences focused on income (8). It revealed that $57 \%$ were female and $43 \%$ were male. Men had a mean salary of $\$ 76,536$ (median, $\$ 74,000$ ), and women had a mean salary of $\$ 72,207$ (median, $\$ 69,500$ ). The survey did not compare employability by sex. In terms of age, the survey did reveal that salary increased as years of experience increased. It also showed that salary increased as the age of the respondent increased. However, it did not look at age independent of years of experience.

A limitation of this study was that only those who took the NMTCB entry-level examination were included. The American Registry of Radiologic Technologists entry-level NMT examination was not used. In addition, the state of the job market during the years that the subjects graduated was depressed. Future research that could control these limitations would be valuable.

\section{CONCLUSION}

Multiple factors are associated with employability. For NMT graduates, these include overall education, GPA, and number of attempts to pass the board examination. For NMT programs, these include number of clinical sites rotated through, number of clinical hours performed, and number of schools within a 100-mile radius. Age, sex, 
program level of education (certificate, associate, or baccalaureate degree), single versus dual certification, and class size did not predict employability.

\section{DISCLOSURE}

No potential conflict of interest relevant to this article was reported.

\section{REFERENCES}

1. Harrell A, Matthews E. Relationship between the number of clinical sites in radiography programs and job placement rates of graduates. Radiol Technol. 2016;87: 617-621.

2. Cronin VR. Message from the president. J Nucl Med Technol. 2006;34(1):2.

3. Perry D. 2012 NMTCB certificant survey results. NMTCB website. http://nmtcb.org/ resources/2012certsurvey.php. Accessed December 12, 2018.
4. Enrollment snapshot of radiography, radiation therapy and nuclear medicine technology programs-2016. ASRT website. https://www.asrt.org/docs/default-source/ research/enrollment-snapshot/enrollment-snapshot-of-radiography-radiation-therapyand-nuclear-medicine-technology-programs-2016.pdf?sfvrsn. Published January 2017. Accessed December 12, 2018.

5. Kwan J, Childs RA, Cherryman F, Palmer C, Catton P. Admission criteria and student success in a medical radiation sciences program. J Allied Health. 2009;38:158-162.

6. Bires AM, Mason DL, Gilmore D, Pietrzyk C. Gap analysis survey: an aid in transitioning to standardized curricula for nuclear medicine technology. J Nucl Med Technol. 2012;40:178-182.

7. Nielsen C, Aaron Laura Aaron, Bolus NE, et al. Curriculum Guide for Educational Programs in Nuclear Medicine Technology. 4th ed. Reston, VA: Society of Nuclear Medicine and Molecular Imaging Technologist Section; 2008.

8. Foster A. 2013 salary survey results. NMTCB website. http://nmtcb.org/documents/ 2013\%20Salary\%20Survey\%20Results\%20final.pdf. Published 2014. Accessed December 12, 2018.

9. Martino S. Computed Tomography in the 21st Century: Changing Practice for Medical Imaging and Radiation Therapy Professionals. Albuquerque, NM: American Society of Radiologic Technologists; 2008. 